\title{
WORLD TRENDS IN PHOTODYNAMIC THERAPY
}

Spinelli P., Dal Fante M.

\author{
Endoscopy Dept., Istituto Nazionale Tumori, Milan, Italy
}

Among the various treatments of cancer, Photodynamic Therapy (PDT) is the only selectively directed to neoplastic cells. It is used for eradication of early tumors and palliation of more advanced disease. Actually, every form of traditional cancer therapy, surgery, radiation, and chemotherapy, involves in the treatment various amounts of the host tissues. We can define PDT as the first local, selective, therapy for cancer. But let us review the principles and the present applications of PDT. Based on the combined effect of a drug-7ight system that produces singlet oxygen with cytotoxic effects, PDT has firstly been used for cancer treatment, by Lipson, Gray and Baldes in 1966, injecting intravenously a specially prepared hematoporphyrin derivative (HPD) as photosensitizing drug (1). Since then, thousands of patients have been treated pointing out the correct indications and the appropriate techniques of PDT.

Treating of the trends of PDT in the different Countries it is advisable to separate the different aspects of a photodynamic system: the drugs, the lights, the clinical approaches. As PDT is based on the combined action of photosensitizer and of the light, both factors must be considered for optimization. A photosensitizer must, ideally, be highly efficient, non-toxic, and selective. A light for the activation of a photosensitizer must be sufficiently penetrating the tumor tissue, easily focused on the optic fiber to be transmitted intracavitary and produced by a reliable and possibly, not too expensive source. After the first attempts using Hematoporphyrin base (HP), that demonstrated a very high skin photosensitizing effect and a limited selectivity for tumor tissue, other drugs have been used for PDT, including HpD, Di-hematoporphyrin ether/ester (DHE), Amino-laevulinic acid (ALA). Practically, at present, Hpd and DHE are clinically used, and respectively known as Photophrin I (PI) and Photophrin II (PII); the latter is a purified and more active form and is the most used in clinical trials; as it is characteristic for porphyrins, it absorbs light with five absorption peaks, the higher being at $400 \mathrm{~nm}$ in the soret band, and the lower being at $630 \mathrm{~nm}$. The last peak is used for PDT, since the light absorption by biological tissues is lower. Deeper penetration of light in tumor tissue means activation of larger quantity of photosensitizer trapped into the tumor and consequently necrosis of larger amounts of tumor tissue. The mechanism of activation consists in absorption of light and excitation of the photosensitizer to a higher singlet state. From this excited state it can either return to the ground-state, or it can change to the lowest excited triplet state, which has a slightly lower 
energy than the first excited single state. The decay time of the triplet state is slow and the sensitizer has time to react with its chemical environment (2). In PDT of tumors the main reaction is a direct energy transfer from the triplet-state sensitizer to molecular oxygen to produce singlet oxygen; it reacts with various chemical substrates to cause oxidation of cellular constituents such as proteins, lipids, and nucleic acids. Oxidation of these cellular constituents interferes with the normal structure and function of irradiated cells resulting in cell death and, finally, tumor necrosis. At the cellular level, plasma membrane, mitochondria, nucleus, and lysosomes have been suggested as the target sites of photodynamic reactions (3). However, studies in vivo suggest that the tumor vasculature may be the main target of PDT, with tumor necrosis caused by the selective damage of the vasculature (4).

\section{PHOTOSENSITIZERS}

A clinically useful photosensitizer should be nontoxic, selectively concentrated in malignant tissues, and activated by penetrating light (wavelength $600 \mathrm{~nm}$ to $800 \mathrm{~nm}$ ). HPD, or its more purified form DHE, are the most widely used photosensitizers for clinical PDT, but these compounds have two major drawbacks: a slow clearance from skin, responsible for photosensitivity of treated patients, and a low absorption efficiency at wavelengths longer than $600 \mathrm{~nm}$. The ALA is a natural porphyrin precursor and its administration is followed by an accumulation of photoactive porphyrin intermediates at different concentrations in different tissues. This is used for photodynamic applications (5) owing to the fact that it has also a negligible photosensitizing effect. Photosensitizers for potential clinical use are Chlorines and Phthalocianines. Among Chlorins, Benzoporphyrin derivative (BPD) is a very interesting lipophilic drug for some important peculiarities, the first one being that its maximum absorption peak is at $690 \mathrm{~nm}$, in a spectral region of deep light penetration. When formulated in a liposomal vehicle it distributes in plasma almost exclusively to the lipoprotein fraction. BPD accumulates rapidly in tumor tissue. Preliminary experimental results suggest a possible high tumor selectivity. The highest levels in tissues are reached 3 hours after the injection and between three and five hours after injection occurs the maximum skin photosensitivity. That seems to be the most appropriate timing for PDT, because after that time the plasma levels and tissue concentration start decreasing, parallel to skin photosensitivity. The response is to be related to the quantity of drug and of light energy. Skin photosensitivity does not extend beyond a few days $(6,7)$. Phthalocyanines are a group of photosensitizers that can be activated at longer wavelength than porphyrines, so that the amount of necrosis 
obtained results to be increased (8). Their phototoxicity is enhanced combining the drug with various metals, such as zinc or aluminium to form Zn-naphthalocyanine of Al-phthalocyanines; sulfonated groups render phtalocyanines water soluble. Wavelengths of 670 or more in the red spectrum are used to activate these compounds, whose primary site of action seems to be the plasma membrane. The presence of oxygen is essential for the process of photoactivation (9).

\section{LIGHT}

Filtered light sources can be used for superficial PDT, but, for most endocavitary applications laser light is essential. There are different laser sources used for PDT: the "traditional" tunable Argon-Dye laser, the Copper and Gold lasers, and the new semiconductor diode lasers. Diode lasers have several advantages over the traditional laser sources: extremely high electrical-to-optical conversion efficiency, small size and portability, lower costs of maintainance $(10)$. Their wavelength between 750 and $850 \mathrm{~nm}$, appears to be appropriate for the future photosensitizers, that should be activated by deeply penetrating lights. A single fiber or a multifiber system can be used to distribute the laser light to the target. Fibers have different shapes, related to the area to be illuminated: sharp-cut fibers are used for forward distribution, while bulbous terminations are used in spherical cavities like the bladder and cylindrical radiating fiber termination are used to irradiate tubular segments as the esophagus, the trachea or the bronchi (11). Further studies on light sources and optimization of light distribution are important points to be developed in the near future.

\section{CLINICAL AREAS FOR FURTHER DEVELOPMENTS}

Biological tissues, and in particular neoplastic tissues, are the target for most of the applications of PDT. The interest of PDT has been initially directed to superficial lesions, but after the first attempts, endocavitary tumors appeared to be suitable for photodynamic treatments. Consequently, PDT has been used alone or in combination with traditional cancer therapies, for curative as well as for palliative treatments, for early as well as for advanced cancers.

In 1980, Hayata at the Tokyo Medical College reported the first endoscopic PDT for bronchial carcinoma (12). This Institution has now accumulated the widest experience in the world, reporting the possibility of curative treatment of early stage lung cancer. Recent results by the same group report around $90 \%$ complete remission in lesions smaller than $1 \mathrm{~cm}$ (13). In 1982, Cortese and Kinsey (14) reported on the eradication of four early stage bronchial tumors treated at the Mayo Clinic. The rate of complete remission decreases in larger lesions probably due to impossibility of uniform laser light 
distribution all over the lesion. In 1985, Balchum and Doiron reported on the results of 72 patients treated for palliation of bronchial obstruction (15). In $98 \%$ of patients a complete recanalization of the airway was obtained and only 3 patients had complications such as mild bacterial pneumonia responsive to antibiotic therapy. The main difference between this study and others was the use of "cleaning" bronchoscopy 2 or 3 days after light irradiation to remove necrotic tissue from the irradiated area. Edell and Cortese (16) identified 13 patients with 14 carcinomas, candidates for surgery but who elected to have PDT: in 13 a complete response was achieved. In 3 patients who had recurrent cancer, surgical resection was curative. They consider PDT as an alternative to surgical resection in early superficial squamous cell carcinoma. Ono e coll (17) reported the results of PDT in 39 radiographically occult tracheobronchial carcinoma: complete response was obtained in 12 and partial in 27 . For the treatment of advanced lung tumors, partially or totally obstructing the lumen of a bronchus, light is delivered to the lesion by a cylindrical diffusing fiber inserted into the residual lumen or into the lesion. A clean-up bronchoscopy is necessary 2-3 days after irradiation to remove necrotic tissue obstructing the airway. At present the role of PDT in the treatment of bronchial obstruction is under evaluation in multicentric studies comparing PDT and thermal laser therapy by Neodymium-YAG laser. PDT has been used also in the symptomatic treatment of malignant pleural effusions, with partial response (18). Ris and associates, reported on the treatment of pleural mesothelioma by m-THPC (meta-TetraHydroxyphenyl Chlorin), a particularly active chlorin compound, performed intraoperatively following surgical resection; the treatment is feasible but it is related to substantial additional morbidity if large surfaces are treated (19).

Cutaneous multicentric, extensive or critically sited primary or recurrent cancers, in whom traditional methods of treatments are considered inappropriate $(20,21)$, cutaneous and subcutaneous metastases from breast carcinoma, Kaposi's sarcoma have been considered as indications (22). For the treatment of basal cell carcinoma, a recent paper by Wilson reports a complete response rate of $88 \%$ after one PDT session (23).

In ENT, cutaneous and mucosal cancer have been reported to respond to PDT (24). Wenig and associates treated 26 patients with squamous cell carcinoma of the oral cavity, oropharinx, maxillary sinus, larynx, parotid gland, head and neck; reporting complete response in $77 \%$ of patients (25). Papillomavirus laringeal papillomas have been submitted to PDT, with a decrease of about $50 \%$ in the average rate of papilloma growth following the treatment; the response was especially pronounced in patients with the worst disease (26).

The response of brain tumors to PDT has been investigated 
$(27,28)$. Irradiation has been performed by the surface after craniotomy or by optic fiber stereotactical implantation and after local or intravenous administration of the photosensitizer. Many questions remain open on the effectiveness of PDT in central nervous system malignancies, although major complications have not been reported.

In the esophagus, both early and advanced lesions have been submitted to PDT. Large, advanced, obstructing lesions responded to PDT allowing palliation of obstruction, but the respective role of PDT and Nd:YAG laser treatment must yet be clarified. In our series of 352 patients treated with Nd:YAG laser alone, recanalization was obtained in $93 \%$ and palliation of dysphagia in $75 \%$ (29). For early superificial small or extended or multicentric esopheal carcinoma, PDT represents an elective indication. In our series early esophageal cancers were successfully treated by endoscopic PDT in 10/13 patients (77\%) after a mean follow-up of 35 months (30). These results are similar to those reported by other Authors $(31,32)$. In the stomach, PDT is generally used to treat early superficial cancers, particularly when they are type IIa, or IIc, or type III according to the classification of the Japanese Society for Gastroenterological Endoscopy. Types I or II a are better treated by electroresection or by Nd:YAG photocoagulation. Mimura, Ichii and Okuda treated with PDT 15 early gastric cancers using Excimer-dye laser and demonstrated that it is more effective than Argon-dye laser (33). The largest experience in the treatment of advanced gastrointestinal cancer is from jin et al (34) in China, with 120 patients. A patient with a tumor of the extrahepatic biliary ducts has been successfully treated (35). At present, the indications for PDT in the large intestine are very limited. However, recently published results have demonstrated that after intravenous injection, adenomas present an uptake of HPD similar to that of carcinomas (36). This observation led us to consider the applicability of endoscopic PDT in case of large flat colorectal adenomas. Krasner et al reported the eradication of $3 / 5$ colorectal large sessile adenomas treated by PDT (37).

In the urinary bladder PDT is used in the treatment of carcinoma in situ, and tumors at stage $T a$ or $T 1$. Some patients had transurethral resection (TUR) of bladder papillary tumors prior to PDT. A focal light irradiation of diseased areas or a whole bladder irradiation can be performed. However, when multicentric lesions were present the whole bladder illumination was preferred. In order to obtain a homogeneous distribution of light dose, the use of a bulb tip fiber, or of a light scattering solution has been proposed. In the former case the bladder is filled with normal saline solution and the bulb of the fiber is positioned at the center of the viscus. In the latter case, the bladder is filled with a lipidic physiological 
suspension (Intralipid, Pierrel, Kabitvitrum, Sweden, 1:1000) and the position of the fiber tip is at a quarter of the distance bewteen the center and the neck of the bladder. Severe reduction of urinary capacity, due to bladder shrinkage, is the most important complication after whole bladder irradiation; it seems to be related to the light dose and to the pressure used to distend the bladder. Harty and associates (38) treated seven patients with bladder tumors stage Ta, $\mathrm{Tl}$, or Tis. A whole bladder irradiation was performed, with a light dose of $25 \mathrm{~J} / \mathrm{cm} 2$, followed by focal treatment of visible lesions $(100$ $\mathrm{J} / \mathrm{cm} 2$ ). Five patients had a marked increase in bladder symptomatology, namely frequency, urgency, dysuria, and hematuria. These symptoms persisted for up to 12 monts in four patients. Light dose of $20 \mathrm{~J} / \mathrm{cm} 2$ and pressure of less than $30 \mathrm{~cm}$ of water can reduce the incidence of irreversible shrinkage and of prolonged urinary symptoms. Recently, a single course of PDT has been proposed for the prophylaxis of tumor recurrences after TUR of superficial transitional cell carcinomas of the bladder. Prophylaxis of tumor recurrence by PDT has been correlated to stimulation of macrophages and lymphocytes within the bladder. In fact, cytokines, interleukin-l and tumor necrosis factor, have been demonstrated in the bladder for months after PDT sessions (39).

Patients with either primary gynaecologic cancer or metastatic lesions from other primary tumor sites have been treated (40). Intraepithelial cancer of the cervix and vulva were also submitted to PDT. The problem of the possible involvement of the deep parts of the cervical glands in the neoplastic process requires further evaluation regarding to treatment with PDT. The effectiveness of PDT in completely destroying the cervical glands remains to be demonstrated. PDT has also been proposed to treat intraperitoneally disseminated malignancies, diffusing laser light through a scattering medium consisting of a solution of Intralipid (Kabivitrum, Alameda, Californial introduced into the peritoneal cavity. The light is delivered through flat-cut fiber held at a fixed distance from the peritoneal surface. PDT is performed after debulking the tumor. The study has demonstrated the feasibility of PDT to peritoneal cavity in therapeutic doses (41).

An interesting clinical aspect of PDT is its association with other treatments and, mainly, with chemotherapy : in 144 patients affected by advanced cardiac cancers an association of Mitomycin $C$ and PDT led to complete remission in $19.5 \%$ of patients (42). Combining PDT with hyperthermia proved to be effective for cancer treatment, as well as glucose administration. This approach requires lower amounts of light and of photosensitizers, minimizing the side-effects (43).

Researchers hope that PDT will be one of the bright spots in the treatment of cancer. 


\section{REFERENCES}

1. Lipson RL, Gray MJ, Baldes EJ. Hematoporphyrin derivative for detection and management of cancer. Proc 9th International Cancer Congress, 393, Tokyo, 1966.

2. Cubeddu R, Ramponi R, Sacchi $C A$ et al. Photophysical properties of hematoporphyrin compounds for tumor diagnosis and therapy. In: Siomos K. Eds: Lasers in Medicine, Proceedings of the First European Workshop on Lasers in Medicine, Crete, Greece, Pelekanakis, 1988, 97-112.

3. Moan J. Porphyrin-sensitized photoinactivation of cells: a review. Lasers Med Sci 1986, 1: 5-12.

4. Dougherty TJ. Photodynamic therapy: New approaches. Sem Surg Oncol 1989, 5: 6-17.

5. Loh CS, Bedwell J, MacRobert AJ, Krasner N, Phillips D, Bown SG. The kinetics of 5-Aminolaevulinic acid photosensitisation in the rat stomach. In: Photodynamic therapy and biomedical lasers. Eds: Spinelli P, Dal Fante M, Marchesini R. Elsevier Publ, Amsterdam, 286-91, 1992.

6. Richter AM et al. Photosensitizing efficiency of two regioisomers of benzoporphyrin derivative monoacid ring A (BPD-MA). Biochem Pharmacol 1992, 43: 2349.

7. Richter AM et al. Photosensitizing potency of structural analogues of benzoporphyrin derivative (BPD) in a mouse tumor model. Brit $J$ Cancer 1991, 63: 87.

8. Wohrle D, Shopova M, Müler S, Mantareva V, Spirov L, Jankov P. Experimental photodynamic therapy with ZN(II)-Naphthalocyanine compounds. In: Photodynamic therapy and biomedical lasers. Eds: Spinelli P, Dal Fante M, Marchesini R. Elsevier Publ, Amsterdam, Milano, 545-8, 1992.

9. Okuda S, Mimura S, Otani T, Imanishi K, Mishima $H$, Ishiguro S, Ichii $M$, Tatsuta $M$. Diagnostic laser fluorescence and photochemotherapy. In: I tumori gastroenterici. Veronesi $U$, Montorsi W, Gennari L, Spinelli P, Emanuelli H. Casa Editrice Ambrosiana, Milano, 387-99, 1984.

10.Pratesi R. Diode laser pumped solid state lasers. In: Optronic techniques in diagnostic and ther. med. Plenum Press, New York, $15-26,1991$.

11. Russo $V$. Optical fiber delivery systems for medical applications. In: Photodynamic therapy of tumors and other diseases. Eds: Jori $G$, Perria C. Progetto Publ, Padova, 371, 1985.

12. Hayata $Y$, Kato $H$, Konaka $C$, Ono J, Takizawa $N$ : Hematoporphyrin derivative and laser photoradiation in the treatment of lung cancer. Chest 1982, 81: 269-77.

13. Kato $\mathrm{H}$, Konaka $\mathrm{C}$, Kawate $\mathrm{N}$, Shinohara $\mathrm{H}$, Kinoshita $\mathrm{K}$, Noguchi $M$, 0otomo S, Hayata Y: Five-year disease-free survival of a lung 
cancer patient treated only by photodynamic therapy. Chest 1986, 90: $768-70$.

14. Cortese DA, Kinsey JH. Endoscopic management of lung cancer with hematoporphyrin derivative phototherapy. Mayo Clin Proc, 57: $543-47,1982$.

15. Balchum 0J, Doiron DR: Photoradiation therapy of endobronchial lung cancer: large obstructing tumors, nonobstructing tumors, and early-stage bronchial cancer lesions. Clin Chest Med 1985, 6: 255-75.

16. Ede11 ES, Cortese DA. Photodynamic therapy in the management of early superficial squamous cell carcinoma as an alternative to surgical resection. Chest 1992, 102: 1319-22.

17. Ono R, Ikeda $S$, Suemasu K: Hematoporphyrin derivative photodynamic therapy in roentgenographically occult carcinoma of the pracheobronchial tree. Cancer 1992, 69: 1696-701.

18. Ris HB, Altermatt HJ, Nachbur B, Stewart JCM, Wang Q, Lim CK, Bonnett $R$, Althaus $U$. Clinical evaluation of photodynamic therapy with mTHPC for chest malignancies. In: Photodynamic therapy and biomedical lasers. Eds: Spinelli P, Dal Fante M, Marchesini R. Elsevier Publ, Amsterdam, 421-5, 1992.

19.Ris HB, Altermatt $H J$, Inderbitzi R, Hess R, Nachbur B, Stewart JCM, Bonnet $R$, Berenbaum MC, Althaus $U$. Photodynamic therapy with chlorins for diffuse malignant mesothelioma: Initial clinical results. Br J Cancer 1991, 64: 1116-20.

20.Sacchini V, Melloni E, Marchesini $R$ et al. Topical administration of tetrasodium-meso-tetraphenyl-porphynesulfonate (TPPS) and red light irradiation for the treatment of superficial neoplastic lesions. Tumori 1987, 73: 19-23.

21.Gregory R0, Goldman L. Application of photodynamic therapy in plastic surgery. Lasers Surg Med 1986, 6: 62-6.

22.Lui $H$, Anderson RR. Photodynamic therapy in dermatology: recent developments. Dermatol $\mathrm{Cl}$ in 1993, 11: 1-13.

23.Wilson BD, Mang TS, Stoll H, Jones C, Cooper M, Dougherty TJ: Photodynamic therapy for the treatment of basal cell carcinoma. Arch Dermatol 1992, 128: 1597-601.

24.Gluckman JL, Waner M, Shumrick K et al. Photodynamic therapy: a viable alternative to conventional therapy for early lesion of the upper aerodigestive tract? Arch Otolaryngol Head Neck Surg 1986, 112: 949-52.

25.Wenig BL, Kurtzman DM, Grossweiner LI et al. Photodynamic therapy in the treatment of squamous cell carcinoma of the head and neck. Arch Otolaryngol Head Neck Surg 1990, 116: 1267-70.

26. Abramson AL, Shikowitz MJ, Mullooly VM, Steinberg BM, Amella CA, Rothstein HR. Clinical effects of photodynamic therapy on recurrent laryngeal papillomas. Arch Otolaryngol Head-Neck Surg 1992, 118: 
25-9.

27.Perria C, Carai M, Falzoi A et al. Photodynamic therapy of malignant brain tumors: Clinical results of, difficulties with, questions about, and future prospects for the neurosurgical applications. Neurosurgery 1988, 23: 557-63.

28.Laws ER, Wharen RE, Anderson RE. Photodynamic therapy of brain tumors. In: Photodynamic therapy of tumors and other diseases. Eds: Jori G, Perria C, Progetto Pub1, Padova,311, 1985.

29.Dal fante M, Spinel1i P, Pizzetti P, Cerrai FG, Mancini A: Survival after endoscopic palliation of malignancies of the upper gastro-intestinal tract with Nd:YAG laser. In: Photodynamic therapy and biomedical lasers. Eds: Spinelli P, Dal Fante M, Marchesini R. Elsevier Publ, Amsterdam, 266-271, 1992.

30.Spinelli P, Dal Fante M, Mancini A, Massetti M. Endoscopic photodynamic therapy of early cancer and severe dysplasia of the esophagus. In: Photodynamic therapy and biomedical lasers. Eds: Spinelli P, Dal Fante M, Marchesini R. Elsevier Publ, Amsterdam, 262-5, 1992.

31. Monnier Ph, Fontolliet Ch, Wagnières G, Braichotte D, Van den Bergh H. Further appraisal of PDI and PDT of early squamous cell carcinomas of the pharinx, oesophagus and bronchi. In: Photodynamic therapy and biomedical lasers. Eds: Spinelli P, Dal Fante M, Marchesini R. Elsevier Publ, Amsterdam, 7-14, 1992.

32. Lambert R, Sibille A, Souquet JC, Sabben G, Descos F. Results of photodynamic therapy in upper gastro intestinal cancer. In: Photodynamic therapy and biomedical lasers. Eds: Spinelli P, Dal Fante M, Marchesini R. Elsevier Publ, Amsterdam, 256-61, 1992.

33. Mimura S, Ichii M, Okuda S. Photodynamic therapy for early gastric cancer using excimer dye laser. In: Photodynamic therapy and biomedical lasers. Eds: Spinelli P, Dal Fante M, Marchesini R. Elsevier Publ, Amsterdam, 272-76, 1992.

34.Jin $M L$, Yang $B Q$, Zhang $W$ et al. Photodynamic therapy for the treatment of advanced gastrointestinal tumors. Lasers Med Sci 1989, 4: $183-6$.

35. McCaughan JS, Mertens BF, Cho C et al. Photodynamic therapy to treat tumors of the extrahepatic biliary ducts. Arch Surg 1992, 126: $111-3$.

36.Dal Fante M, Bottiroli G, Spinelli P: Behavior of hematoporphyrin derivative in adenomas and adenocarcinomas of the colon: a microfluorometric study. Lasers Med Sci 1988, 3: 165-71.

37. Krasner $N$, Chatlani PT, Barr H. Photodynamic therapy of tumors in gastroenterology: A review. Lasers Med Sci 1990, 5: 233-8.

38. Harty JI, Amin M, Wieman TJ et al. Complications of whole bladder dihematoporphyrin ether photodynamic therapy. J Urol 1989, 141: $1341-6$. 
39. Nseyo $U$, Whalen $R$, Duncan $M$ et al. Urinary cytokines following photodynamic therapy for bladder cancer. Urology 1990, 36: 167-71.

40. Corti L, Maluta S, Tomio L, Stevanin C, Iannone T, Calzavara F: Photodynamic therapy in gynecological cancer. Lasers Med Sci 1989, 4: $155-8$.

41. Sindelar WF, DeLaney TF, Tochner $Z$ et a1. Technique of photodynamic therapy for disseminated intraperitoneal malignancies: Phase I study. Arch Surg 1991, 126: 318-24.

42.Jin ML, Yang BQ, Zhang W, Ren P. Combined treatment with photodynamic therapy and chemotherapy for advanced cardiac cancers. J Photochem Photobio1 B 1992, 12: 101-6.

43. Nelson JS, Kimel S, Brown L, Berns MW. Glucose administration combined with photodynamic therapy of cancer improves therapeutic efficacy. Lasers Surg Med 1992, 12: 153-8. 